\title{
INFLUENCE OF MODELING OF TURBULENCE IN THE FLOW PARAMETERS WITHIN A FOOD OVEN USING THE OPENFOAM $^{\circledR}$
}

\author{
S. A. Verdério Júnior ${ }^{\mathrm{a}}$, \\ V. L. Scalon ${ }^{b}$, \\ and A. Padilha ${ }^{c}$ \\ Universidade Estadual Paulista \\ "Júlio de Mesquita Filho" \\ Departamento de Engenharia Mecânica \\ Faculdade de Engenharia de Bauru \\ Bairro Vargem Limpa \\ Bauru, São Paulo, Brasil \\ CEP 17033-360 \\ asilviover_jr@yahoo.com.br \\ bscalon@feb.unesp.br \\ cpadilha@feb.unesp.br \\ Received: October 29, 2015 \\ Revised: November 24, 2015 \\ Accepted: December 04, 2015
}

\section{ABSTRACT}

Because of the better flexibility in warming and high production, the continuous furnace tunnel is the better option to the processing of industrialized food products. This study presents a numerical investigation of the effects of RANS turbulence modeling on the main parameters of the air flow inside a continuous oven with indirect heating - velocities, temperatures, streamlines and heat flows by convection and radiation. The geometry and operating conditions used for constructing the model, setting the mesh and initial and boundary conditions were obtained based on values of operating ovens. Modeling consider the hypothesis of air as an ideal gas, incompressible and Newtonian; the equations of continuity, momentum balance and energy in turbulent regime; closing model of two equations $\kappa-\varepsilon$ and radiation model viewFactor. Utilized the free open source software OpenFOAM $^{\circledR}$ for device modeling. The Rayleigh Number of the cavity was used to evaluate the treatment indicated to turbulence. Considering the results obtained, the inclusion of model $\kappa-\varepsilon$ stabilized the velocity fields and temperatures around the average value. In relation to the heat exchanges involved, heat flow by convection on the mat showed negligible compared to the effects of radiation. Due to the discrepancy between the orders of magnitude of convection and radiation, it's difficult the precise evaluation of the first, because small fluctuations in temperature and velocity affect considerably and induce oscillations in their behavior. However, the radiation model attained good approximation the most relevant exchanges, showing a good chance their application in practical cases.

Keywords: thermal simulation, numerical analysis, radiation model, turbulence modeling, OpenFOAM ${ }^{\circledR}$

\section{NOMENCLATURE}

$C_{p} \quad$ specific heat at constant pressure, $\mathrm{J} / \mathrm{kg} . \mathrm{K}$

$C_{v} \quad$ specific heat at constant volume, J/kg.K

$C_{\varepsilon 1} \quad$ empirical constant of model k- $\varepsilon\left(C_{\varepsilon 1}=1.44\right)$

$C_{\varepsilon 2} \quad$ empirical constant of model k- $\varepsilon\left(C_{\varepsilon 2}=1.92\right)$

$C_{\mu} \quad$ empirical constant of model k- $\varepsilon\left(C_{\mu}=0.09\right)$

$E_{b_{j}} \quad$ emissive power of black body, $\mathrm{W} / \mathrm{m}^{2}$

$F_{i j} \quad$ view factor

$g_{i} \quad$ vector acceleration of gravity, $\mathrm{m} / \mathrm{s}^{2}$

$G_{0_{i}} \quad$ external radiation that reaches the surface analysis, $\mathrm{W} / \mathrm{m}^{2}$

$i \quad$ counter or index of summation $(i=1,2,3, \ldots)$

$j \quad$ counter or index of summation $(j=1,2,3, \ldots)$

$q_{\text {rad }}$ total heat flow by radiation, $\mathrm{W} / \mathrm{m}^{2}$

$\bar{q}^{(v)} \quad$ viscous heat flux, $\mathrm{W} / \mathrm{m}^{2}$

$\bar{q}^{(t)} \quad$ turbulent heat flux, $\mathrm{W} / \mathrm{m}^{2}$

$p \quad$ static pressure, $\mathrm{N} / \mathrm{m}^{2}$

$\bar{P} \quad$ component average of pressure in the RANS model, $\mathrm{N} / \mathrm{m}^{2}$

$R \quad$ gas constant, J/kg.K

$R a \quad$ Rayleigh Number

$R a_{t} \quad$ Turbulent Rayleigh Number

Re Reynolds Number

Ri Richardson Number

$t$ time, s

$T$ temperature, $\mathrm{K}$

$\bar{T} \quad$ average temperature, $\mathrm{K}$

$u_{i} \quad$ floating components of velocity in the RANS model, $\mathrm{m} / \mathrm{s}$

$U$ velocities field, $\mathrm{m} / \mathrm{s}$

$\bar{U}_{i} \quad$ average components of velocity in the model RANS, m/s

$\tilde{U} \quad$ internal energy, $\mathrm{J} / \mathrm{kg}$

$x \quad$ coordinate $\mathrm{x}, \mathrm{m}$

$y$ coordinate $\mathrm{y}, \mathrm{m}$

$\mathrm{z}$ coordinate $\mathrm{z}, \mathrm{m}$

\section{Greek symbols}

$\alpha_{t} \quad$ turbulent thermal diffusivity, $\mathrm{m}^{2} / \mathrm{s}$ 
$\beta \quad$ coefficient of volumetric thermal expansion, $\mathrm{K}^{-1}$

$\delta_{i j} \quad$ Kronecker delta function

$\varepsilon \quad$ viscous dissipation rate of turbulent kinetic energy, J/kg.s

$\varepsilon_{j} \quad$ emissivity

$\kappa \quad$ turbulent kinetic energy, $\mathrm{J} / \mathrm{kg}$

$\mu \quad$ dynamic or absolute viscosity, $\mathrm{kg} / \mathrm{m} . \mathrm{s}$

$\mu_{t}$ dynamic or absolute viscosity turbulent, $\mathrm{kg} / \mathrm{m} . \mathrm{s}$

$v \quad$ kinematic viscosity, $\mathrm{m}^{2} / \mathrm{s}$

$v_{t} \quad$ turbulent kinematic viscosity, $\mathrm{m}^{2} / \mathrm{s}$

$\rho \quad$ density or specific mass, $\mathrm{kg} / \mathrm{m}^{3}$

$\bar{\rho} \quad$ density or specific mass evaluated in $\overline{\mathrm{T}}$ for use in the Boussinesq model

$\sigma_{\varepsilon} \quad$ empirical constant of model k- $\varepsilon\left(\sigma_{\varepsilon}=1.3\right)$

$\sigma_{\kappa} \quad$ empirical constant of model k- $\varepsilon\left(\sigma_{\kappa}=1\right)$

$\bar{\Phi}_{v}^{(t)}$ thermal dissipation function of the turbulent kinetic energy, $\mathrm{s}^{-2}$

$\bar{\Phi}_{v}^{(v)}$ viscous dissipation function, $\mathrm{s}^{-2}$

\section{INTRODUCTION}

The increasing world population, the decrease in food supply and the largest food sector costs show the need for better understanding and optimization of food processing processes. Besides, changes in consumer profile looking for agreeable food, of longer life and at the same time healthier, with fewer calories and reduced content of sugar, sodium, gluten, trans fats, etc. are increasingly evident. Thus, the study, modeling and optimization of processes and food ovens seek to meet these demands with the lowest possible power consumption (Associação Brasileira das Indústrias de Alimentação - ABIA, 2010. Available in http://www.abia.org.br/vs/vs conteudo.aspx?id=29 and accessed on 03/08/2015).

The oven is a very important device in an industrial installation. It requires a significant initial investment, a complex maintenance and adjustment and delicate operation. The ovens are usually classified according to the heating system, the fuel type, the heat transfer system and the type of feed used.

The Continuous ovens are used for large-scale production. In this type of device, the products that are automatically loaded, are processed and, in the end, are discharged. They have usually length of 25 $\mathrm{m}$ or more and are divided into zones, with conditions of temperature, humidity and velocity controlled according to the type of product being processed. They have still moving surfaces, which are structured in steel belts or material ceramic or conveyor mats (Fellows, 2006 and Matz, 1992).

In indirect heating ovens, the combustion gases do not come into contact with the product. The atmosphere of the ovens is heated by a system heat exchangers, where each region has a burner. They may use fuel oil, gas, solid fuel or electricity. Its main feature is to provide greater heating system design flexibility, being possible facilitate radiation mechanism by placing more tubes or heating resistors and the mechanism of forced convection through the warm air circulation within the chamber (Fellows, 2006 and Matz, 1992).

The main objective of this work is the numerical investigation of the effects of turbulence modeling, using RANS method with the model of two equations $k-\varepsilon$, on the main parameters of the flow (velocity and temperature fields, heat fluxes, streamlines and velocity profiles) of a continuous oven with indirect heating. Differently from a series of studies made by Anishaparvin et. al. (2010), Chhanwal et. al. (2010), Tank et. al. (2014) and Mondal and Datta (2010), the present study aims to evaluate the parameters and physical condition of the air flow inside the oven without considering its effects directly on the heat transfer on a particular product being processed. For the boundary conditions were established temperatures as from measured values in a real oven. For the elaboration of numerical model was used and free software and opensource OpenFOAM ${ }^{\circledR}$ for performing the numerical simulation of flow and profiles the velocity and temperature.

\section{PHYSICAL MODEL}

\section{Oven Geometry}

The geometry of the oven studied has cross section of $1.5 \mathrm{~m}$ wide, $0.5 \mathrm{~m}$ in height and longitudinal length of $23.6 \mathrm{~m}$. The dimensions and operational conditions used in building the model are similar to the real oven to pre-baking pizzas, used in a food company.

The physical model was divided into different regions for fixing initial and boundary conditions, as can be seen in Figures 1 and 2. In this scheme can be highlighted some most important regions to the study:

- OPEN INLET $(z=0)$ and OPEN OUTLET $(z=$ 23.6) - no restrictions to airflow from inside the oven and representing large energy losses.

- CLOSED INLET $(z=0)$ and CLOSED OUTLET $(z=23.6)-$ metal plates to obstruction of the airflow from inside the oven.

- BURNERS $(y=0.5)$ - set of various burners tubes present in the upper region of the oven, passing throughout the all extent longitudinal, and represented by a single surface with uniform temperature and equal to $300^{\circ} \mathrm{C}$.

- SIDES - walls sides of the oven and MAT $(y=0)$ conveyor.

These regions are characterized by similar boundary conditions and defined in the simulation as 
patches.

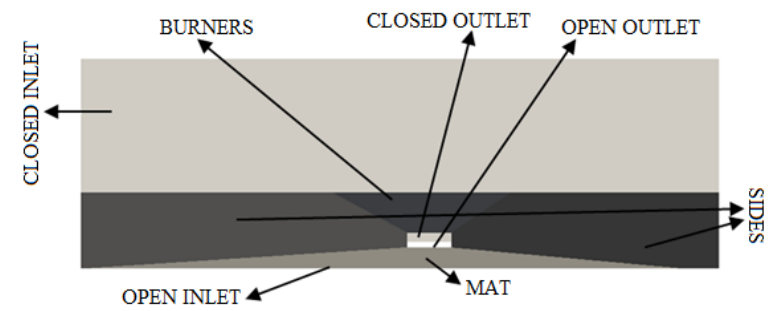

Figure 1. Front view of the physical model.

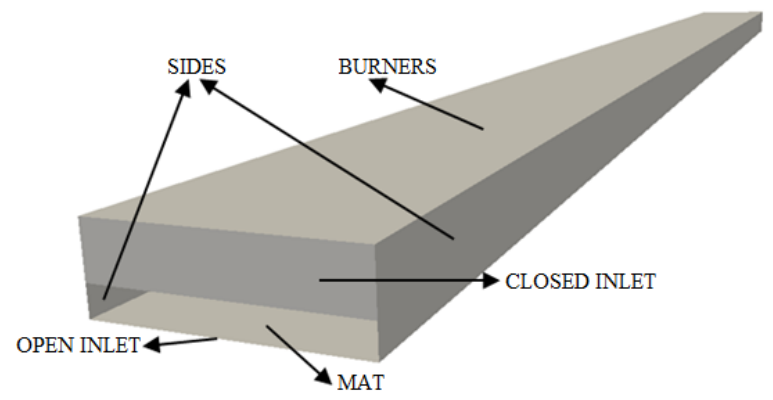

Figure 2. Isometric view of the physical model.

\section{Governing Equations}

In the selection of the governing equations and definition of the mathematical model to be solved, several simplifying assumptions and physical models were adopted. Based on the physics of the problem and typical conditions established in Bird et. al. (2004), Versteeg and Malalasekera (2007) and Modest (2003), were used the following conditions and equations for the solution:

$$
\begin{gathered}
p=\rho R T \\
\tilde{U}=C_{v} T \\
\frac{\partial \bar{U}_{i}}{\partial x_{i}}=0 \\
+\frac{\partial}{\partial x_{j}}\left[\begin{array}{c}
\left.\left(\mu+\mu_{t}\right)\left(\frac{\partial \bar{U}_{i}}{\partial x_{j}}+\frac{\partial \bar{U}_{j}}{\partial x_{i}}\right)\right]+\bar{\rho} g_{i}(1-\beta(T-\bar{T})) \\
\bar{U}_{j} \frac{\partial \bar{U}_{i}}{\partial x_{j}}=-\frac{\partial\left(\bar{P}+\frac{3}{2} \kappa\right)}{\partial x_{i}} \\
\frac{\partial \kappa}{\partial t}+\frac{\partial}{\partial x_{j}}\left(\bar{U}_{j} \kappa\right)=-\frac{\mu_{t}}{\rho}=C_{\mu} \frac{\kappa^{2}}{\varepsilon} \\
\frac{u_{i} u_{j}}{\partial \bar{U}_{i}}
\end{array}\right.
\end{gathered}
$$

$$
\begin{gathered}
+\frac{\partial}{\partial x_{j}}\left[\left(v+\frac{v_{t}}{\sigma_{\kappa}}\right) \frac{\partial \kappa}{\partial x_{j}}\right]-\varepsilon \\
\frac{\partial \varepsilon}{\partial t}+\frac{\partial}{\partial x_{j}}\left(\bar{U}_{j} \varepsilon\right)=-C_{\varepsilon 1} \frac{\varepsilon}{\kappa} \overline{u_{i} u_{j}} \frac{\partial \bar{U}_{i}}{\partial x_{j}} \\
-C_{\varepsilon 2} \frac{\varepsilon^{2}}{\kappa}+\frac{\partial}{\partial x_{j}}\left[\left(v+\frac{v_{t}}{\sigma_{\varepsilon}}\right) \frac{\partial \varepsilon}{\partial x_{j}}\right] \\
\rho C_{p} \frac{D T}{D t}=-\left(\nabla \cdot\left(-\bar{q}^{(v)}+\bar{q}^{(t)}\right)\right)+\mu\left(\bar{\Phi}_{v}^{(v)}+\bar{\Phi}_{v}^{(t)}\right) \\
\sum_{j=1}^{N}\left[\frac{\delta_{i j}}{\varepsilon_{j}}-\left(\frac{1}{\varepsilon_{j}}-1\right) F_{i j}\right] \cdot q_{r a d_{j}}= \\
\sum_{j=1}^{N}\left[\delta_{i j}-F_{i j}\right] E_{b_{j}}-G_{0_{i}}
\end{gathered}
$$

Where:

- Equation of state for ideal gas to the air inside the oven, as equations (1) and (2);

- The other physical properties were assumed constant and evaluated in the average temperature of the $450 \mathrm{~K}$, as shown in Table 1 ;

- Hypothesis of flow incompressible and Newtonian;

- Utilization the algorithm SIMPLE for the coupling pressure-velocity;

- Transient simulation until the convergence of the solution for the steady state;

- Utilization of the equation of continuity in turbulent regime - equation (3);

- Utilization of the balance equation of momentum in turbulent regime and model of Boussinesq to inclusion of field strengths - equation (4);

- Modeling of the turbulence through the RANS method with the model of two equations $(k-\varepsilon)$, accordance with the equations (5) and (7) and constants shown in Table 2;

- utilization of energy conservation equation in turbulent regime - equation (8);

- Radiation model viewFactor for heat exchanges between surfaces with non-participating media equation (9).

Table 1. Physical properties used.

\begin{tabular}{c|c}
\hline$\overline{\mathrm{T}}$ & $450 \mathrm{~K}$ \\
\hline$v$ & $3.239 .10^{-5} \frac{\mathrm{m}^{2}}{\mathrm{~s}}$ \\
\hline$\mu$ & $2.507 .10^{-5} \frac{\mathrm{kg}}{\mathrm{m} \cdot \mathrm{s}}$ \\
\hline$\alpha$ & $4.72 .10^{-5} \frac{\mathrm{m}^{2}}{\mathrm{~s}}$ \\
\hline
\end{tabular}




\begin{tabular}{|c|c|}
\hline $\bar{\rho}$ & $0.744 \frac{\mathrm{kg}}{\mathrm{m}^{3}}$ \\
\hline$C_{p}$ & $1021 \frac{\mathrm{J}}{\mathrm{kg} . \mathrm{K}}$ \\
\hline$\beta$ & $2.264 .10^{-3} K^{-1}$ \\
\hline $\operatorname{Pr}$ & 0.686 \\
\hline $\operatorname{Pr}_{t}$ & 0.7 \\
\hline$\vec{g}=\left(\begin{array}{lll}g_{x} & g_{y} & g_{z}\end{array}\right)$ & $\left(\begin{array}{lll}0 & -9.81 & 0\end{array}\right) \frac{m}{s^{2}}$ \\
\hline
\end{tabular}

Table 2. Empirical conditions usually utilized in the turbulence model $\mathrm{k}-\varepsilon$.

\begin{tabular}{c|c|c|c|c}
\hline $\mathrm{C}_{\varepsilon 1}$ & $\mathrm{C}_{\varepsilon 2}$ & $\mathrm{C}_{\mu}$ & $\sigma_{\kappa}$ & $\sigma_{\varepsilon}$ \\
\hline 1.44 & 1.92 & 0.09 & 1.0 & 1.3 \\
\hline
\end{tabular}

\section{Experimental Data Survey}

A similar oven of a food industry was utilized to collect the experimental data the process of prebaking of pizzas. These informations were used in the oven geometry, mesh construction and definition of some initial and boundary conditions. The temperatures used were collected by an infrared thermometer contactless, brand Raynger ${ }^{\circledR}$, model MX4, with laser sighting and adjustable emissivity.

\section{Boundary Conditions}

The initial and boundary conditions used are defined according to the real conditions in each patch. The Table 3 illustrates the boundary conditions utilized to different patches defined. Those tables show how to implement the physical conditions through typical commands of OpenFOAM ${ }^{\circledR}$, according with The Open Source CFD Toolbox User Guide (2014, available in http://foam.sourceforge. net/docs/Guidesa4/UserGuide.pdf and accessed on 25/10/2015) and The Open Source CFD Toolbox Programmer's Guide (2014, available in http://foam.sourceforge.net/docs/Guidesa4/Programm ersGuide.pdf and accessed on: 25/10/2015). The equivalence to physical conditions and boundary is detailed throughout the rest of this section.

Table 3. Initial and boundary conditions.

\begin{tabular}{|c|c|c|c|}
\hline & p & $\mathbf{U}$ & $\mathbf{T}$ \\
\hline Open Inlet & \multirow{7}{*}{ 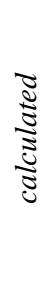 } & $\left(\begin{array}{lll}0 & 0 & 0.1\end{array}\right)$ & $310.15 \mathrm{~K}$ \\
\hline Open Outlet & & inletOutlet & $\nabla T=0$ \\
\hline Closed Inlet & & \multirow{4}{*}{$\left(\begin{array}{lll}0 & 0 & 0\end{array}\right)$} & $310.15 \mathrm{~K}$ \\
\hline Closed Outlet & & & $\nabla T=0$ \\
\hline Sides & & & \\
\hline Burners & & & $573.15 \mathrm{~K}$ \\
\hline Mat & & $\left(\begin{array}{lll}0 & 0 & 0.1\end{array}\right)$ & $336.65 \mathrm{~K}$ \\
\hline
\end{tabular}

Table 3. (cont.) Initial and boundary conditions.

\begin{tabular}{|c|c|c|c|c|}
\hline & alphat & p_rgh & $\mathbf{G}$ & IDefault \\
\hline Open Outlet & \multirow{7}{*}{ 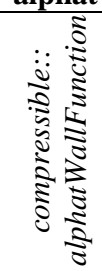 } & \multirow{7}{*}{ 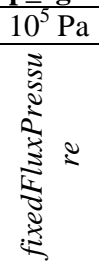 } & \multirow{7}{*}{ 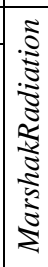 } & \multirow{7}{*}{ 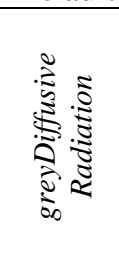 } \\
\hline Open Inlet & & & & \\
\hline Closed Inlet & & & & \\
\hline Closed Outlet & & & & \\
\hline Sides & & & & \\
\hline Burners & & & & \\
\hline Mat & & & & \\
\hline
\end{tabular}

Table 3. (cont.) Initial and boundary conditions.

\begin{tabular}{|c|c|c|c|c|}
\hline & $\mathbf{Q}_{\mathbf{r}}$ & Epsilon & $\mathbf{k}$ & mut \\
\hline Open Inlet & \multirow{7}{*}{ 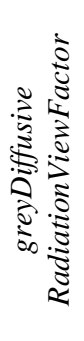 } & \multirow{7}{*}{ 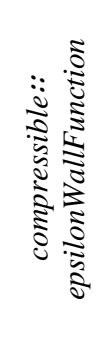 } & \multirow{7}{*}{ 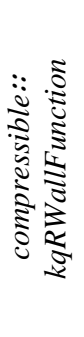 } & \multirow{7}{*}{ 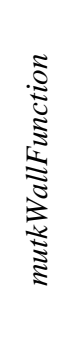 } \\
\hline Open Outlet & & & & \\
\hline Closed Inlet & & & & \\
\hline Closed Outlet & & & & \\
\hline Sides & & & & \\
\hline Burners & & & & \\
\hline Mat & & & & \\
\hline
\end{tabular}

The static pressure (p) is calculated from the total pressure, excluding it the field effect (p_rgh). The condition fixedFluxPressure defines the pressure gradient from the mass flow at the boundaries. This term and void if not impermeable walls.

The velocity condition (U) for the region of open outlet, inletOutlet, is a condition output mixed. In the case of positive flow applies to condition zeroGradient $(\nabla U=0)$ and in the case of negative flow applies to uniform velocity condition is equal to (ll 000 ), as specified in the variable inletValue.

The temperature of the mat was estimated as the simple arithmetic average of the air inlet temperature ( $\mathrm{T}=310.15 \mathrm{~K}$ ) and the outlet temperature of final product of mat $(\mathrm{T}=363.15 \mathrm{~K})$, experimentally measured.

Alphat is the turbulent thermal diffusivity $\left(\alpha_{t}\right)$. Calculated using the frontier condition compressible::alphatWallFunction, which provides a condition of turbulent diffusivity, used to capture the effects near the wall for turbulent flow with low Reynolds Number (Re).

The boundary conditions for radiation are defined by parameters $\mathrm{G}$, IDefault and $\mathrm{Q}_{\mathrm{r}}$, The greatness $G$ is the incident radiation, calculated from the temperatures field of previous time step, through the standard boundary condition MarshakRadiation. IDefault is the intensity of radiation and the boundary condition greyDiffusiveRadiation establishes the behavior of gray and diffuse body. $Q_{r}$ is the flow of heat by radiation, calculated using the condition greyDiffusiveRadiationViewFactor. This procedure provides a boundary condition of gray and diffuse body for use in radiation model viewFactor.

The turbulent conditions are defined by the variables of some additional greatnesses turbulent. Epsilon $(\varepsilon)$ is the viscous dissipation of turbulent 
kinetic energy calculated by the frontier condition compressible::epsilonWallFunction, which is indicated for turbulent flows with high Reynolds Number. The turbulent kinetic energy $(\kappa)$ is calculated using the frontier condition compressible:: $k q R W a l l F u n c t i o n$, which imposes a condition of zero gradient. The turbulent viscosity, mut $\left(\mu_{t}\right)$, is calculated by the condition mutkWallFunction and which provides a wall function based on the turbulent kinetic energy.

\section{Numerical Model}

The free and opensource software OpenFOAM $^{\circledR}$, version 2.4 .0 , is used in the numerical simulation. The construction of the geometry is defined using keypoints, where the definition of mesh parameters is made in the preprocessor blockMesh. The resolution of algebraic linear equations obtained through the discretization of the transport equations by Finite Volume Method (FVM) was performed by a own solver for modeling, present in OpenFOAM ${ }^{\circledR}$. The post-processing is made through the other opensource software - the paraView.

The solver used is the buoyantSimpleFoam, which is characteristic for compressible flow, laminar or turbulent and incorporated into the algorithm of the coupling pressure-velocity the transport equations, SIMPLE. Has pre-implanted into the source code the mechanisms of the heat exchange by radiation and compressibility models.

\section{Mesh}

Various softwares, commercial and free, are shown as options for the construction of the geometry and mesh definition, highlighting the GAMBIT $^{\circledR}$ and SALOME $^{\circledR}$. However, in this study we opted for the application of the blockMesh, present in OpenFOAM $^{\circledR}$. Although construction process is more complex, because it involves several geometric calculations, is capable of generating structured meshes and adequate for executed simulation, reducing the computing power demanded. However, the use of this code for geometries of great complexity and with many details is difficult to become viable. The application blockMesh decomposes the geometry of the physical domain studied in a set of one or more of hexahedral threedimensional blocks.

\section{RESULTS AND DISCUSSION}

Initially, for the definition of size of the element was performed a test of independence and consistency of the mesh. Where used were elements of $0.20 \mathrm{~m}$ and 4284 points; $0.175 \mathrm{~m}$ and 5440 points; $0.15 \mathrm{~m}$ and 6952 points; $0.125 \mathrm{~m}$ and 12350 points; $0.10 \mathrm{~m}$ and 22752 points; $0.075 \mathrm{~m}$ and 46452 points; $0.06 \mathrm{~m}$ and 92196 points and $0.05 \mathrm{~m}$ and 161293 points - totaling eight tests.

The temperatures field in the left side wall in the central region of the oven after $3600 \mathrm{~s}$ simulation, for each test and is it used as a parameter for analyzing and comparing different mesh sizes and, is illustrated in Figure 3.

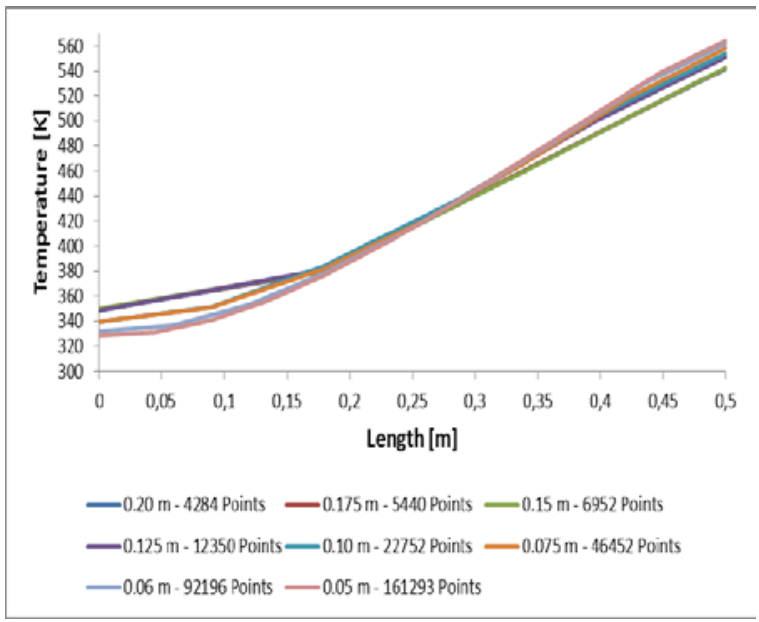

Figure 3. Comparison between the temperatures fields in the left side wall central in $3600 \mathrm{~s}$ of simulation for eight different mesh sizes.

It is observed in these results that the meshes with elements of $0.06 \mathrm{~m}$ and 92196 points and $0.05 \mathrm{~m}$ and 161293 points they showed to be more appropriate to do the simulations, with a maximum deviation compared to more refined mesh of the order of $1.31 \%$. Thus, by questions of smaller demanding of computing power, we opted for the use of mesh with elements of $0.05 \mathrm{~m}$ and 161293 points. The Figure 4 illustrates the mesh with the chosen element.

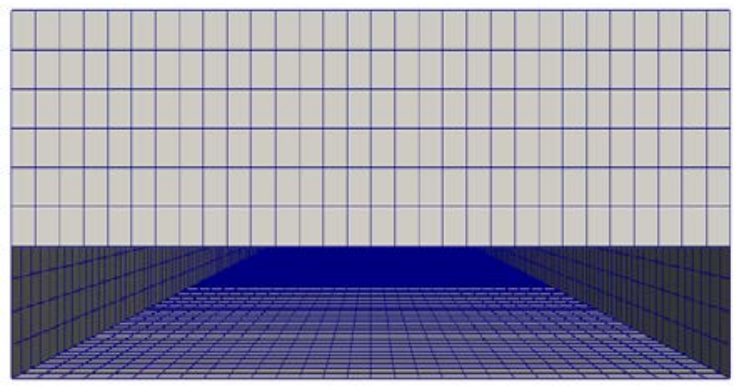

Figure 4. Front view of computational mesh with the use of cubic control volumes and homogeneous with $0.05 \mathrm{~m}$ edges.

The Figures 5 a 7 show the effects of the inclusion of turbulence model in the flow equations. In Figures 5 and 6 have, respectively, the curves of velocities and temperatures for the central region, in total length of the oven and in height $y=0.25$. In Figure 7 are shown the temperature curves for the walls in the center, $z=11.8$, throughout the oven height. 


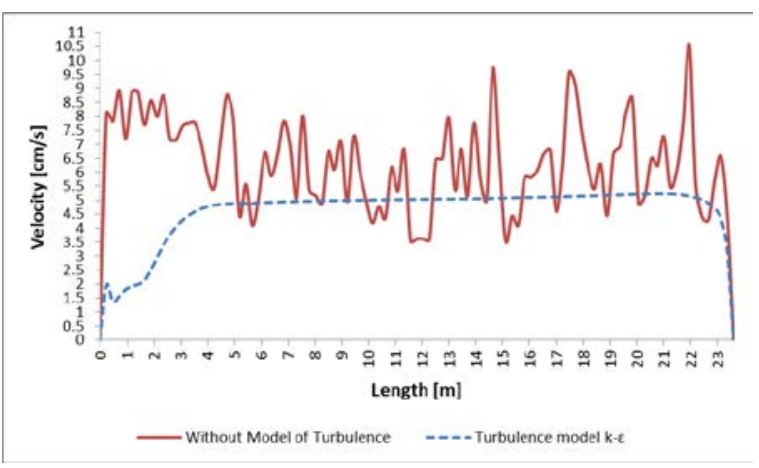

Figure 5. Velocities curves for the central region of the oven.

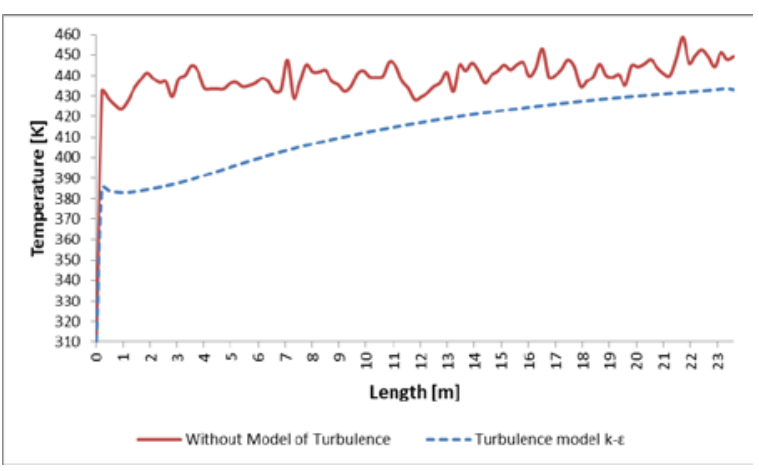

Figure 6. Temperature curves for the central region of the oven.

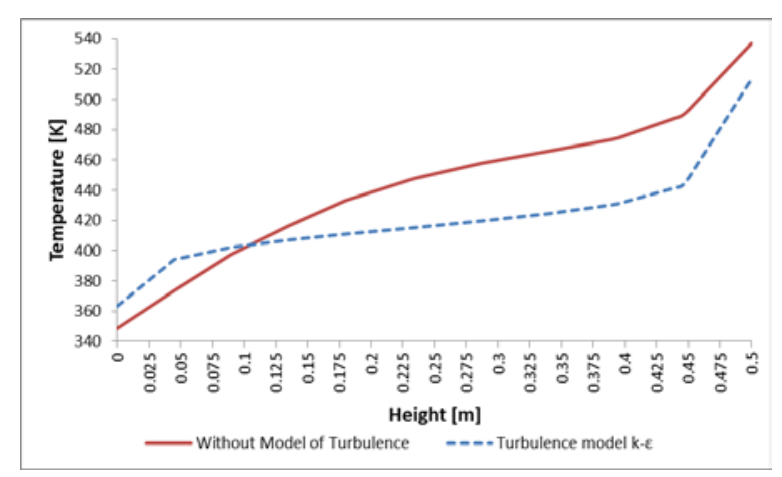

Figure 7. Temperature curves for walls in the central region of the oven.

Analyzing the results, for the model without turbulence of the treatment shown in Figures 5 and 6, are visible oscillations in temperatures and velocities in the center of the oven, featuring a flow around a mean value. The presence of typical perturbations this regime of flow, as vortices and stagnation regions, not allowed the stabilization of the temperature and velocity fields. Furthermore, the value of Rayleigh Number $(\mathrm{Ra})$ to the displayed flow is $\mathrm{Ra}=4.295 .10^{8}$. According Incropera et. al. (2006), empirical results for cavities with heating in the upper region show that changing of the flow regime to turbulent, happens when $\mathrm{Ra}>5.10^{4}$. Although the geometries are not identical, it is expected that the order of magnitude of the Turbulent Rayleigh
Number $\left(\mathrm{Ra}_{\mathrm{t}}\right)$ does not change significantly. Therefore, the treatment of turbulence by the method RANS and with the model of two equations $(k-\varepsilon)$ was implemented in the proposed solution. The RANS turbulence modeling eliminates the observed oscillating behavior, stabilizing the fields of temperatures and velocities.

From the above, to the center of the oven, observe it in Figure 6 that the oscillating behavior of temperatures in the model without treatment of the turbulence is approximated by a uniform increase curve. For velocity curve, as shown in Figure 5, has its approximation in a curve almost constant and equal to $5 \mathrm{~cm} / \mathrm{s}$, except for the initial and final regions of the oven.

For the walls in the center of the oven, shown in Figure 7, observed it the approximation with a behavior more stable, and with lower temperatures gradients that the model without treatment of turbulence. Again, the exceptions are the initial and final parts of the oven.

The Figures 8 and 9 show the results of streamlines for the model without treatment and with treatment of RANS turbulence, respectively.

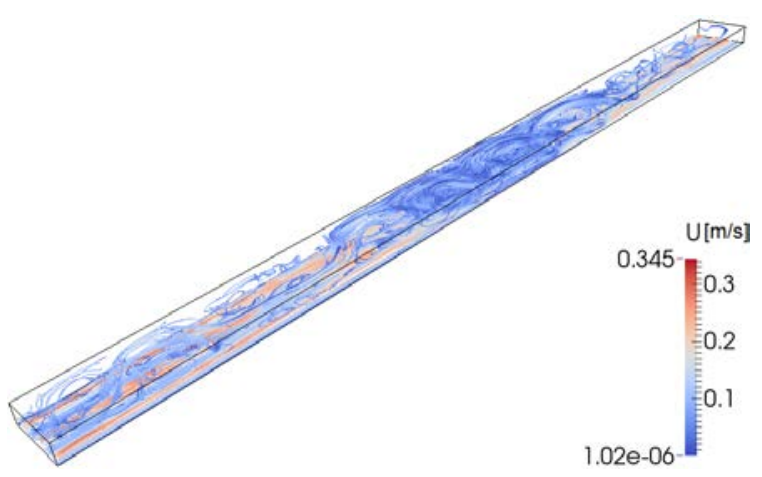

Figure 8. Isometric view of streamlines, based on the velocities and to the entire length of the oven, without treatment of turbulence.

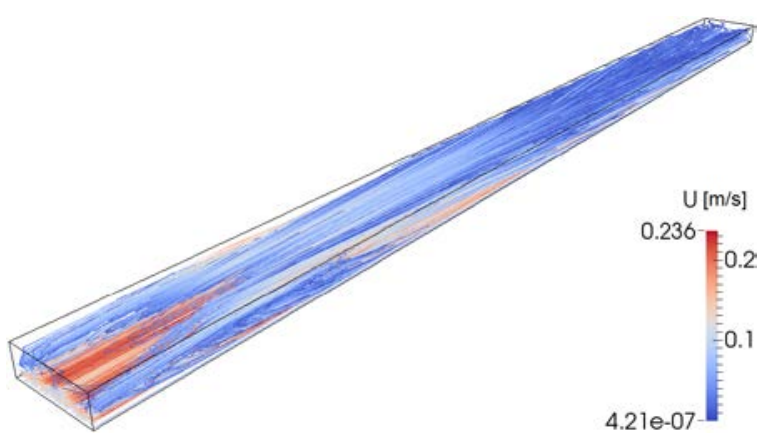

Figure 9. Isometric view of streamlines, based on the velocities and to the entire length of the oven, with the RANS turbulence modeling.

In Figure 8, in without treatment model of turbulence, observed an irregular flow, characterized by the presence of recirculations, vortices and zones of stagnation throughout the entire interior of the 
oven. It is observed still that the air has more velocity near of the mat, and has less velocity in the regions of the burner, being characterized various subregions of stagnation. Noteworthy is also the forming a larger thermal plume, comprehended in the upper region of the oven in the range $\mathrm{z}=9$ and $\mathrm{z}=14$. As a result is formed in this region a stagnation zone with high temperatures and near-zero velocities.

The Figure 9, turn, shows the resulting average behavior of flow with modeling turbulence. Note also, in this case, the presence of a thermal plume of high dimension, but located in the upper region of the oven from $\mathrm{z}=16$.

The Figures 10 and 11 show the velocity profiles for the cross section $\mathrm{z}=11.8$, exactly in the center of the oven for the model without treatment and with treatment of RANS turbulence, respectively.

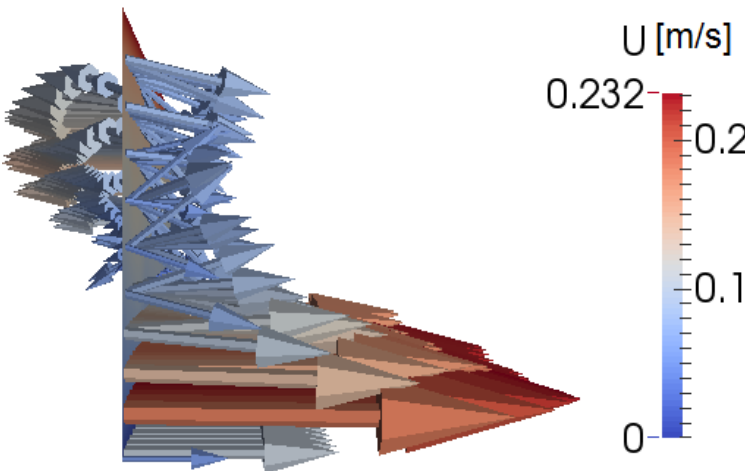

Figure 10. Velocities profiles for cross section $\mathrm{z}=$ 11.8 for the model without treatment of turbulence.

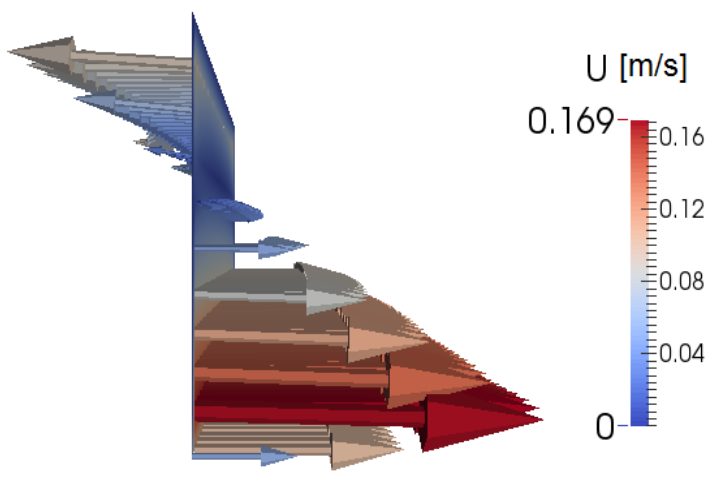

Figure 11. Velocities profiles for cross section $\mathrm{z}=$ 11.8 for the model with RANS treatment turbulence.

For the model without treatment of turbulence, shown in Figure 10, it is observed that near of the mat, has a regular profile and maximum velocities of the order of $23 \mathrm{~cm} / \mathrm{s}$. Besides, when approaching the burner, the velocity profile becomes quite irregular, characterizing several regions of the recirculation in flow.

By analysis of Figure 11, with modeling of turbulence, it is observed that, near the mat with $\mathrm{y}<$ $0.34 \mathrm{~m}$, there is a progressive movement, with maximum velocities of the order of $16.9 \mathrm{~cm} / \mathrm{s}$. Then, in position $\mathrm{y}=0.34 \mathrm{~m}$ it has the reversal of motion. For the region where $\mathrm{y}>0.34 \mathrm{~m}$ and when approaching the burner, there is a reverse motion, with velocity profile linear medium, with maximus in the order of $8 \mathrm{~cm} / \mathrm{s}$.

Finally, was evaluated the influence of inclusion of turbulence model in heat transfer rates by radiation, convection and liquid in mat, as illustrated in Figures 12, 13 and 14, respectively. Table 4 shows the integrated results for the entire mat surface.

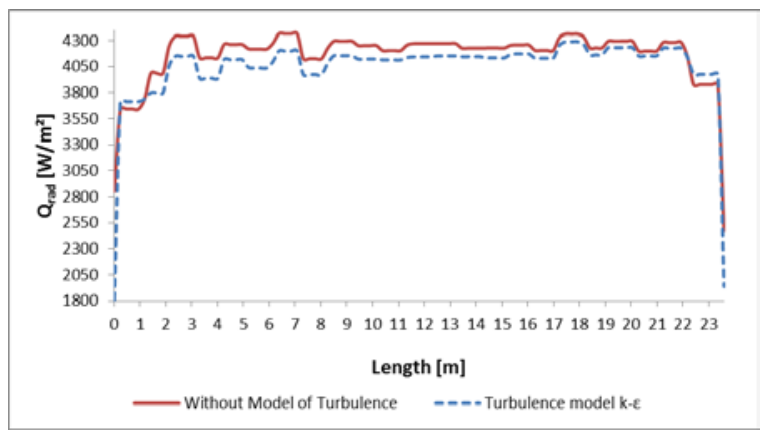

Figure 12. Heat transfer by radiation on mat.

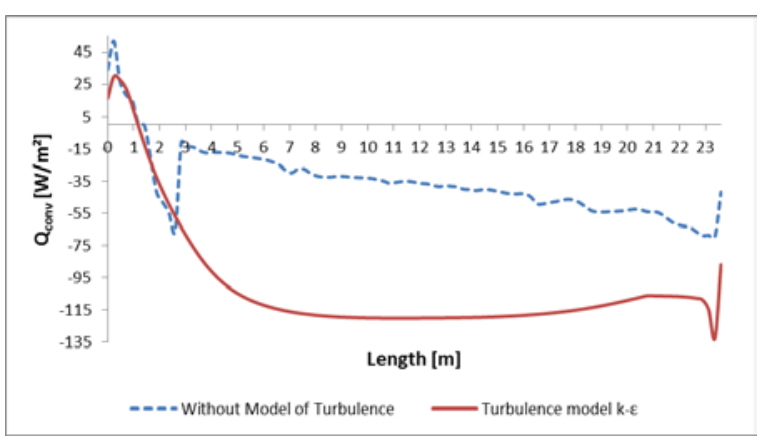

Figure 13. Heat transfer by convection on mat.

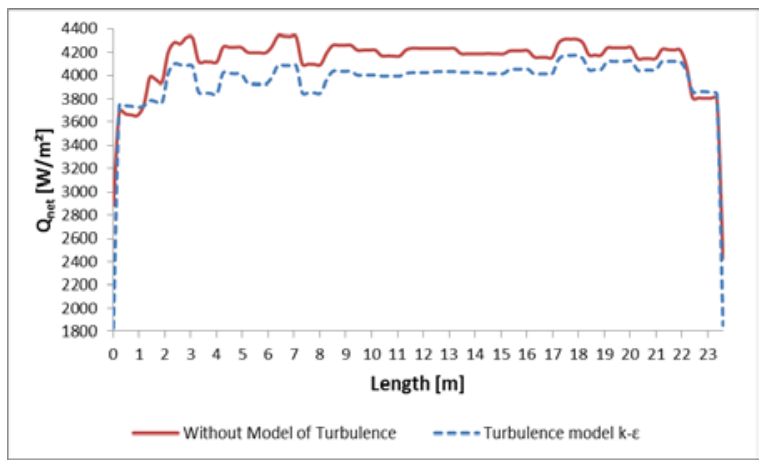

Figure 14. Net heat transfer on mat.

Table 4 . Heat transfer by radiation and convection integrated into the mat.

\begin{tabular}{c|c|c|c}
\hline & $\mathbf{Q}_{\text {rad }}$ [W] & $\mathbf{Q}_{\text {conv }}$ [W] & $\mathbf{Q}_{\text {net }}$ [W] \\
\hline $\begin{array}{c}\text { Without Model } \\
\text { of Turbulence }\end{array}$ & 148203 & -1240.75 & 146962.3 \\
\hline $\begin{array}{c}\text { Turbulence } \\
\text { model k- } \varepsilon\end{array}$ & 144671 & -3442.42 & 141228.6 \\
\hline
\end{tabular}


To evaluate which regime of convection prevails - convection natural, forced or mixed - has it the calculation of Richardson Number (Ri). For the flow studied, has it $\mathrm{Ri}=0.128$, which the characterizes it as a flow with forced convection, because $\mathrm{Ri}<<1$, according Incropera et. al. (2006).

The Figure 13 and Table 4 show that modeling of the turbulence affected significantly the convection transfer rates; increasing the in 2.77 times. It is noteworthy that the mat continues losing heat; however, observed a more regular profile, which tends to stabilize in $-115 \mathrm{~W} / \mathrm{m}^{2}$.

It is noteworthy that, in both models, the order of magnitude of convection is much lower than radiation. Thus, small variations of temperatures and velocities affect significantly the behavior of heat transfer in this region and cause significant fluctuations in their behavior.

In relation to transfers by radiation, as shown in Figures 12 and Table 4, with modeling of turbulence is observed a very similar profile but slightly lower; with a difference of $2.38 \%$ in relation to the integrated. Were not really expected changes in this case, once when using a radiation model of type viewFactor, these depend only on the geometry of the problem. Thus, the small oscillations observed may be the result of their own estimate based on statistical points and used for determining the view factors.

Finally the analysis of the net rates of heat transfer, as shown in Figure 14 and Table 4, demonstrates the agreement of results in both models; with an order error $4 \%$ relative to the total integrated. It is also observed that the curve of Figure 14 has practically the same format as that in Figure 12, which is due to the small influence of heat transfer by convection. Thus, it is concluded that modeling from turbulence had little influence on heat exchanges by radiation and net.

\section{CONCLUSIONS}

In the study of ovens presented, was observed that exchange of heat by convection is of order of magnitude lower the radiation. Thus, it seems impossible the modeling of ovens with consistent physical results, without the use of an appropriate model for the evaluation of radiation.

By the discrepancy between the intensities of heat exchange by radiation and convection, it becomes difficult the correct evaluation of the latter. This is due the fact that small variations of temperatures and velocities affect significantly the behavior of heat transfer by convection, and induce significant variations in their behavior.

The results illustrate the necessity of turbulence modeling for the solution of the flow. The inclusion of model of two equations $(\mathrm{k}-\varepsilon)$ in the turbulence modeling presented the small influence on net heat exchanges over the mat, because predominates the heat exchange by radiation. Despite this, was observed a stabilization effective of the results, eliminating transient fluctuations that were occurring in laminar transient model.

\section{ACKNOWLEDGEMENTS}

The authors acknowledge with gratitude the financial support granted by CAPES.

\section{REFERENCES}

Anishaparvin A., Chhanwal N., Indrani D., Raghavarao K. S., and Anandharamakrishnan C., 2010, An Investigation of Bread-Baking Process in a Pilot-Scale Electrical Heating Oven Using Computational Fluid Dynamics, Journal of Food Science, Vol. 75, No. 9, pp. 605-611.

Bird, R. B., Stewart, W. E., and Lightfoot E. N., 2004, Transport Phenomena, 2nd, John Wiley \& Sons.

Chhanwal, N., Anishaparvin, A., Indrani, D., Raghavarao, K., and Anandharamakrishnan, C., 2010, Computational Fluid Dynamics (CFD) Modeling of an Electrical Heating Oven for BreadBaking Process, Journal of Food Engineering, Vol. 100, No. 3, p. 452-460.

Fellows, P. J., 2006, Tecnologia do Processamento de Alimentos: Princípio e Prática, $2^{\mathrm{a}}$ edição, Artmed. (in Portuguese)

Incropera, F. P., Dewitt, D. P., Bergman T. L., and Lavine, A. S., 2008, Fundamentos da Transferência de Calor e de Massa, 6ª Edição, LTC. (in Portuguese)

Matz, S. A., 1992, Bakery Technology and Engineering, 3rd edition, Pan-Tech International.

Modest, M. F., 2003, Radiative Heat Transfer, 2nd edition, Academic Press.

Mondal, A., and Datta, A. K., 2010, TwoDimensional CFD Modeling and Simulation of Crustless Bread Baking Process, Journal of Food Engineering, Vol. 99, No. 2, pp. 166-174.

Tank, A., Chhanwal, N., Indrani, D., and Anandharamakrishnan, C.., 2014, Computational Fluid Dynamics Modeling of Bun Baking Process Under Different Oven Load Conditions, Journal of Food Science and Technology - Mysore, Vol. 51, No. 9, pp. 2030-2037.

Versteeg, H. K., and Malalasekera, W., 2007, An Introduction to Computational Fluid Dynamics The Finite Volume Method, 2nd Edition, Longman Scientific and Technical. 